\title{
La guerra sin tregua: una crónica periodística
}

Milagros Aguirre*

$\mathrm{E}$ stamos en guerra en la selva ecuatoriana. Lo hemos dicho una y otra vez, desde hace al menos, el 2003. Hemos repetido una y otra vez la misma historia, añadiendo capítulos violentos año tras año, pero la misma historia, hasta el cansancio. Estamos en guerra. Una guerra silenciosa que se desarrolla en el corazón de la selva. Una guerra desigual, de lanzas contra escopetas. La crónica de una muerte anunciada. O mejor, la crónica de una sentencia de muerte. El punto final parece que llegará solamente cuando ya no quede ninguno, cuando ya no queden cuerpos para tantas balas, cuando la selva se haya tragado sus pisadas, sus cantos, sus secretos. La guerra ha tenido algunos protagonistas que se han ubicado en esa primera línea de fuego y lanzas: en el siglo XX, los misioneros evangélicos, los trabajadores del petróleo, Alejandro Labaka junto a Inés Arango, en sus intentos de contacto pacífico. En el siglo XXI algunos trabajadores de la madera, una familia campesina, los waorani Ompure y Buganey (2013) y ahora la más reciente víctima, Caiga Baihua (2016), un joven y trabajador motorista wao que vivía del turismo, víctima de las lanzas mortales.

La sonrisa de Caiga aún permanece en el recuerdo: tantas veces que, como buen motorista, acompañó a los promotores de la Fundación Labaka a visitar Shiripuno, Ñoneno, Bameno y Boanamo. El cocinaba cuando era hora de acampar, quien sabía muy bien tratar con los turistas y con los invitados cowode ${ }^{1}$ El que ayudaba a explicar a sus compañeros sobre vivir en paz con los vecinos, sobre el respeto al territorio -Ome Yasuní-; Caiga bromeaba, ayudaba a los demás. Era el hijo de Omayuhe (uno de los viejos waorani de quien se dice que ha tenido visitas y contactos amistosos por parte de los tageri/taromenani) hermano de Otobo y de Bartolo, dos jóvenes dedicados al turismo en el corazón del Yasuní.

Hasta ahora no hay versión oficial de cómo murió Caiga. Todo son rumores, cuentos de la selva mezclados con épica y fantasías, sueños, miedos. Sabemos que el ataque fue en pleno río Shiripuno (Yasuní) por donde pasan siempre los turistas para ir a una de las comunidades más famosas y visitadas: Bameno. Dicen que fueron cuatro hombres desnudos. Onenka, que estaba con Caiga, se salvó: estuvo en el hospital Eugenio Espejo de Quito y es, de acuerdo a informaciones en Twitter (que es ahora como informan las autoridades) testigo protegida de la

* Inició su carrera periodística en diarios Hoy y El Comercio, siendo reportera y editora de cultura. Poco a poco se fue especializando en temas amazónicos, vinculada con el Cicame y el Vicariato Apostólico de Aguarico. Desde el 2009 hasta el 2016 fue directora de la Fundación Alejandro Labaka. Actualmente se desempeña como Editora General de Abya-Yala y mantiene una columna de opinión en diario El Comercio y en revista Mundo Diners.

1 Cowode es como les dicen los wao a los otros (mestizos, campesinos, turistas). 
Fiscalía, es decir, que nadie más que personal de esa institución puede hablar con ella para saber lo que ocurrió, incluido el personal del Ministerio de Justicia, que es el ente responsable de la protección de los grupos aislados o no contactados.

Como en la selva no hay secretos pero sí, cuentos y rumores: que Caiga estaba cortando un palo con la motosierra para abrir el paso del río que estaba con muy poca agua, que el ruido a lo mejor molestó a los cazadores tagaeri o, tal vez, lo confundieron con un extraño. Pero el de Onenka parece un cuento de la literatura fantástica o de una de esas películas de aventuras: sobrevive al ataque e incluso uno de los lanceros, que se llamaría Inihua pues dice su nombre y conversa con ella, desata las amarras de la canoa y la empuja: "si vives, vivirás", le dice, mientras los otros tres jóvenes siguen picando el cuerpo de Caiga. Ella, herida, con una lanza en la espalda y otra en el muslo, logra conducir la canoa aguas abajo hasta llegar a Boanamo. Al llegar malherida le dice a uno de sus cuñados: "vaya busque a su hermano que está allá, muerto".

La misma condición, la de testigo protegida, tiene C. una de las niñas raptadas en el asalto que vengó la muerte de Ompure en el 2013. Es decir, lo que pueda contar C. de su familia, de sus casas, de los nombres de sus parientes, de cuántos serían los sobrevivientes de ese ataque y demás, es secreto de Estado, es decir, no se sabrá nunca, hasta que la frágil memoria contribuya al velo de confusiones existentes sobre este tema.

La de Caiga Baihua es una más de las muertes — anunciadas - que ocurren en la selva del Yasuní. Desde el 2003 hemos seguido el tema, hemos visto muertos, hemos acompañado funerales, hemos escuchado el llanto de familias y hemos tenido pesadillas y noches de desvelo con solo imaginar los gritos de terror luego de recabar algunos testimonios de muertes, sobre todo, de mujeres y de niños.

En el 2003, una incursión de los wao a una casa en el Cononaco acabó con una veintena de personas. La muerte se dio, de acuerdo a lo que pude recoger en esa ocasión, porque la mujer de Carlos Omene lloraba. Estaba triste por su esposo muerto diez años antes y clamaba aún, venganza². Los madereros que buscaban cedro y talaban ilegalmente el bosque, aprovecharon la llamada de la venganza y, se dice, apoyaron a los wao con combustible y armas para acabar con los tagaeri. Los wao fueron a matar, cortaron la cabeza a un hombre, lancearon mujeres y niños y los pincharon "como a los monos". Lo decidieron en una fiesta, que es donde se deciden estas cosas.

En el 2005 los "ocultados", como preferimos llamarlos (aunque les dicen aislados o "no contactados"), mataron a un hombre. En el 2006, a otro. En el 2008 a otro más. Tres trabajadores de la madera, muertos (España, Castellanos, Angulo) y uno herido (Moreira). En el 2009 fueron contra una familia campesina en una vía colona (mataron a una mujer y dos hijos y se llevaron a un bebé al que devolvieron más tarde). En el 2013 mataron al matrimonio Ompure y Buganey, dos ancianos de la comunidad de Yarentaro, y pocos días más tarde, la familia de Ompure fue a vengar esas muertes, a la usanza cultural de ellos, matando a no sabemos cuántos, pese a que se advirtió $^{3}$ en el 2013, como se advierte hoy, que, de no intervenir las autoridades, va a haber otra y otra más.

En cada una de las muertes (waoranis y campesinos) la reacción estatal es, casi siempre, la misma: helicópteros aterrizando con funcionarios en la Brigada 19 Napo, declaraciones políticas de ir hasta las últimas consecuencias, tinta gastada en los periódicos con la crónica roja y con poca información, comunicados de las organizaciones ambientalistas culpando exclusivamente al petróleo de los hechos violentos, y unos procedimientos notariales y alguacilescos que no ayudan a poner en vigor las políticas de protección que el país supuestamente tiene, al

2 En el año 1993, Carlos Omene murió lanceado cuando devolvía a una chica, Omatuki, raptada por Babe Ima. Su esposa pedía a los hombres de la comunidad que vengaran esa muerte. Este relato se publicó en la revista Iconos 17 (FLACSO, 2003) y luego en el libro El Exterminio de los Pueblos Ocultos de Miguel Ángel Cabodevilla (Cicame, 2003). http://biblioteca.clacso.edu.ar/ar/libros/ecuador/flacso/iconos/ICONOS\%2017/ICONOS\%2017\%20completa.pdf

3 La Fundación Labaka y el Vicariato de Aguarico advirtieron a las autoridades en su momento, acerca de la urgencia de hablar con los waorani, indemnizar a las familias por un principio de justicia y reparación y acordar con ellos que no pueden incursionar en territorio de los tagaeri/taromenani. Eso consta en el libro Una tragedia ocultada, publicada por Cicame en 2013. 
menos, desde el $2007^{4}$ y que se resumen en intangibilidad, reparación, autodeterminación, precaución, pro-homine, no contacto. Más bien estos procedimientos judiciales contribuyen al ocultamiento de los hechos en lugar de a su esclarecimiento (pinchazos telefónicos, peritajes inútiles, amedrentamiento a quienes escriben o saben algo del tema, división entre waoranis, juicios sin pies ni cabeza y un largo etcétera que, por cierto, le deben costar plata al Estado).

Hasta ahora no hay una versión oficial de los hechos ni de Caiga ni de ningún otra víctima de esta guerra silenciosa. Y tampoco la habrá pues en ninguno de los casos se ha entregado una. Porque a este tema se lo ha judicializado, se lo ha tratado como la historia de un crimen (irresuelto, por cierto), cuando en realidad es un tema de Derechos Humanos, de Derechos de los Pueblos Indígenas y del cumplimiento de unas políticas de Estado. Se ha dado pie a que jueces, fiscales y abogados argumenten perlas como las que nos hemos cansado de anotar: que no se pueden resolver los casos porque no hay cédulas. Que como no hay cuerpos entonces no hay delito (aunque hayan ido al lugar de los hechos 8 meses luego de sucedidos, por ejemplo, los hechos del 2013). Que no se puede llamar a declarar a los Tagaeri o Taromenane porque evidentemente están ocultos o que, luego de un peritaje realizado luego de mojar un algodón con agua oxigenada y untarlo en la punta de una de las 30 lanzas clavadas en el vientre de la señora muerta el 2009, de cómo resultado "que en la lanza había restos de sangre humana".

¿Qué se ha aprendido en estos diez años? Al parecer, poco, muy poco, o nada. Seguimos repitiendo lugares comunes mientras se pierden vidas inocentes. Ni es este un tema exclusivamente entre clanes ni es un tema exclusivamente petrolero. Ni los indígenas llamados aislados ni aquellos en contacto inicial viven en el paraíso, ni son hermanos del alma: se han matado, se temen, están en tiempos de guerras y cobrando venganzas.

Evidentemente su territorio ha sido mermado. Hemos agredido la selva de forma perversa. Ninguna actividad se ha detenido al menos por el principio de Precaución ${ }^{5}$. Sigue la sísmica por los alrededores; se insiste en los trabajos en el campo Armadillo pese a todas las evidencias y avistamientos de los que el Ministerio de Justicia tiene amplia información; se concesionan bloques en el sur, por el Curaray, donde también se sabe de la presencia de grupos de indígenas ocultos; siguen abriéndose vías y ampliándose carreteros (se amplió la vía Maxus, se abrió la carretera del bloque 31); se amplían caminos vecinales en Nueva Esperanza y en otros límites del Parque Nacional Yasuní; siguen volando helicópteros sobre sus casas y chacras, sus ríos se han contaminado ahora incluso con mata-maleza, pesticidas que sustituyen al barbasco y que los indígenas están utilizando para pescar sin ningún control; siguen los derrames y estos contaminan las fuentes de agua; se sigue talando madera; $y$, tampoco, se han detenido las incursiones de algunos waorani a las casas y cercanías de los tagaeri/taromenani; las fincas se multiplican y se adentran en los límites del parque, se escucha el vuelo de avionetas nocturnas y algunas gentes hacen cacería donde no deben.

Paradójicamente hoy se tiene más información sobre la presencia de los grupos ocultados (aislados o no contactados), mejor normativa, más lugares de vigilancia y control, monitoreo más científico, un mapeo más exacto gracias a los GPS y a la tecnología, leyes que amparan a los indígenas. Existen también planes de contingencia y se entiende que ahora el Estado sí cumplirá, y con ello se reparará a la familia de Caiga. Esperemos que así sea. Están establecidas también, unas recomendaciones dadas por una Comisión Especial para la investigación del caso del 2013 nombrada por el Ejecutivo para el efecto (en un informe que no se ha hecho público pero que se sabe que contiene recomendaciones y conclusiones que el país debiera debatir).

4 http://www.sosyasuni.org/en/files/politica_nacional_pav_versinfinal.pdf

5 El principio de precaución se refiere a la toma de decisiones públicas en forma oportuna y adecuada, en situaciones donde la información disponible para ello es insuficiente, donde la información es incompleta o confusa y en situaciones donde precisamente deben ser tomadas a pesar de las dificultades o complejidades. La precaución exige tomar medidas preventivas en caso de incertidumbres o dudas sobre acciones, políticas o actividades que puedan llegar a afectar la vida, y la integridad física, cultural y territorial de los pueblos en situación de aislamiento voluntario: documento de Política Nacional de Pueblos en Aislamiento (2007). 
Sin embargo, el tema se ha vuelto tan complejo y grave pues se han multiplicado los conflictos: en el sector llamado vía Auca, los conflictos de límites entre campesinos, waorani y evidencias de presencia de "ocultados"; en la zona de Dikaro, conflictos por el juicio que lleva a cabo la Fiscalía contra 17 guerreros waorani; en la zona de Kawimeno por la ausencia de dineros petroleros por los trabajos del ITT; en la zona Cononaco por la baja del turismo que será consecuencia directa de la muerte de Caiga, solo por mencionar algunos.

Estos no se solucionarán solamente con la reparación económica a la familia de Caiga, sino con el trabajo permanente y acompañamiento a los waorani, el cumplimiento a sus demandas (que no son pocas de acuerdo al documento que Nawe presentó a los Ministerios ${ }^{6}$ ) y el trabajo, que por ahora nadie hace, de explicación de las leyes y de una mejor convivencia a las familias waorani. Entre los waorani están quienes aún hablan de proteger la selva y quieren un territorio para los Tagaeri y Taromenani y respetar su aislamiento (como el grupo de Penti, en Bameno). Pero están también quienes quieren terminar con ellos definitivamente pues constituyen una amenaza para sus propias vidas. Todos tienen miedo. Y el miedo suele ser un arma muy peligrosa.

\section{La pena alcanza a los wao hasta donde no llega la protección}

Pocos días después de la muerte de Caiga, a uno de sus hermanos le encontraron, digamos, con las manos en la masa: dos carabinas, algunas balas y cinco cajas de cartuchos. Guerra es guerra y la guerra no admite indiferencia. Menos mal, en esta ocasión las autoridades hicieron control de armas, aunque las circunstancias de la detención de los hermanos no fueron muy claras. Días antes, por radio, algunos waorani comentaban que es obligación de un guerrero ir a la venganza y soplaban para que se encienda el fuego de la ira sobre la familia de Caiga.

En esta ocasión, a diferencia de lo que ocurrió cuando murió Ompure, se hicieron dos cosas que mostrarían al menos un mínimo avance a la inoperancia estatal:

a) Se ofreció una indemnización a la familia de Caiga (en principio unas casas para la comunidad, bonos y beca para sus hijos).

b) Se hizo control de armas. E incluso se haría una tercera:

c) Medidas sustitutivas para los infractores, alegando el tema de interculturalidad.

Todo eso sazonado con algunas infortunadas decisiones, como aquella en la que un juez multicompetente decide el arresto domiciliario para los infractores pero en un lugar que no es su domicilio... ni siquiera en un lugar que le pertenezca al Estado y a alguna de sus instituciones... ¡Volvieron por unos días a un albergue privado, perteneciente al Vicariato de Aguarico y a la Fundación Alejandro Labaka, un centro de detención domiciliaria! Cosas que solo suceden en... Macondo pues no hay ley que permita decidir a un juez cosa semejante. Con ello dejaron un mal precedente para que una casa particular, sea de quien sea, se vuelva, por obra y gracia de una decisión judicial, un lugar vigilado por la policía de donde no pueden salir unas personas que no viven ahí...

Lo que no se hizo -ni se hará- es indagar a profundidad sobre la procedencia de esas armas de fuego y la procedencia del dinero para comprarlas. Eso parece ser mejor no saber. Como tampoco se quiere saber de cosas encontradas en las casas del asalto del 2013, como ropas que nadie sabe cómo han ido a parar a esas casas escondidas en la selva, o, peor, alimentos y enlatados que habrían costado la vida a algunos de acuerdo a una primerísima declaración del Fiscal General de la Nación en el 2013 y de lo que no se volvió a hablar nunca más.

Tampoco se habla de la dificultad de aclarar las competencias de unas y otras instituciones que se pisan los talones, se contradicen en sus acciones, han hecho ofrecimientos y las

6 Este documento puso Nawe sobre la mesa en Puyo, al otro día de la muerte de Caiga y evidencia los convenios incumplidos con los waorani. 
comunidades -indígenas pero también campesinas- no se fían ya de ninguna. Definitivamente, no hay coordinación entre instituciones y cada quien hace, respecto a este tema, lo que se le ocurre. Difícil acertar sin una política clara, unos protocolos o procedimientos a seguir (aunque en este último incidente se haya seguido alguno...). En esta ocasión, además, el juez ha actuado solicitando algunas cosas básicas: presencia de los involucrados una vez cada cierto tiempo ante el juez, cursos y capacitación en derechos humanos a quienes fueron detenidos. Algo es algo. Aunque el Estado les alcanza a los wao con su pena, lo que no les puede darles en protección: ahí siguen, expuestos algunos, a ser víctimas nuevamente de la lanza mortal o a ser tentados por el sentimiento de venganza y rabia que aflora en cualquier momento o, simplemente, a dejarse llevar por el miedo.

Judicializar el tema no solo que no ha ayudado, sino que ha prendido la llama del conflicto en varios puntos del territorio Waorani, volviéndolo un campo minado: mecha encendida en la zona Maxus -Dikaro y Yarentaro- con el juicio por homicidio que se sigue contra 17 waorani; mecha encendida en Tiwino-Bataboro, con el juicio seguido a una mujer por la muerte de dos trabajadores de una empresa estatal llamada Ecuador Estratégico. Mecha encendida con el juicio de terrorismo y sabotaje seguido contra algunos Waorani por haber participado en un paro contra la Petrobell.

Se ha seguido un juicio penal inconsistente en el caso de 2013, se ha dado a los waorani señales confusas. Basta un ejemplo: un día el propio Presidente fue a Guillero, Yasuní, sector Maxus - en septiembre de 2013 - y para los wao de Dikaro y Yarentaro esa fue una señal de que se acabó el problema. Tanto, que le regalaron al Presidente una lanza de sus enemigos como trofeo. Pero días después fueron sometidos a la justicia ordinaria — en noviembre de 2013-; unos llevados presos, otros no; una niña quedó con quienes la capturaron y la otra, no pues las autoridades la sacaron en helicóptero de la escuela y la llevaron a otra comunidad (Bameno, Cononaco); un día los liberan (de cargos de genocidio) y días más tarde los vuelven a acusar por homicidio en un proceso judicial por la matanza del 2013 que lleva dos años y medio. Si para nosotros (cowode) es difícil entender a los waorani, la lógica de las autoridades - que se supone son competentes - es inentendible del todo. Eso sí, son eficaces en una sola cosa: en ocultar los hechos relacionados con los pueblos indígenas aislados y crear más confusión.

La zona es un campo minado: hay conflictos entre indígenas y campesinos, entre indígenas y petroleras, entre campesinos y petroleras, entre nacionalidades (kichwas y waorani), entre moradores de la zona y autoridades a las que ven con desconfianza. Una madeja que cada vez se hace más grande y en la que es cada vez más difícil encontrar la punta del ovillo.

\section{Algunas coartadas}

Como en las novelas policiales, en estas muertes amazónicas todos tienen su coartada. El Estado las presenta para descargarse de cualquier violación de la que puedan ser acusados desde la CIDH: judicializar el tema, criminalizar a los Waorani y hacerlos cargar todo el peso de la ley, sin asumir ninguna responsabilidad ni sobre los aislados ni sobre la seguridad de los vecinos, que también han sido víctimas de las lanzas.

El último informe de la CIDH (diciembre 2013) titulado Pueblos Indígenas en aislamiento voluntario y contacto inicial en las Américas, ya recoge algunos puntos de preocupación sobre la vulneración de derechos en Ecuador y sobre los sucesos de marzo de 2013. El Estado ecuatoriano responde a la CIDH mostrando como trofeo su marco jurídico, aunque, en el terreno, las leyes no se aplican ni se cumplen, quedando estos grupos en total indefensión.

Las respuestas que el Estado ha dado a la CIDH son parte de la coartada que tiene para justificar su inoperancia y dejación. Ojo. No su intervención directa en las muertes enunciadas, pero sí, en su incapacidad para resolver conflictos, hacer propuestas, para controlar la zona y a sus variadas gentes, para poner orden en el desorden en el que se ha convertido, poco a poco, la Amazonía ecuatoriana. En el histórico abandono de las minorías - que no dan votos, por cierto- . En la desidia. En la falta de cumplimiento de las leyes que el Estado mismo ha dictado y de las que se ufana. 
Ecuador responde (de acuerdo al documento de Procuradoría) señalando errores procesales en el trámite de peticionarios ante la CIDH. Probablemente tenga razón. Probablemente los abogados ecuatorianos metidos en este caso no tengan ni la suficiente información ni la suficiente experticia sobre el tema. Seguramente hay inconsistencias. Pero lo que es seguro es que hay un caso: en la última década se han producido al menos dos matanzas a indígenas pertenecientes a familias que aún permanecen sin mayor contacto con la sociedad nacional y que habitan en las profundidades de la Amazonía ecuatoriana.

El Estado ha intentado demostrar que los hechos no guardan relación entre sí. Que son hechos aislados unos de los otros (matanza 2003/matanza 2013). Pues no. No resultan acontecimientos aislados unos de otros. Todos los hechos tienen al menos dos denominadores comunes:

- la presión en el territorio de los pueblos indígenas llamados en aislamiento es cada vez mayor, están cercados, asediados, no tienen muchas posibilidades de sobrevivir.

- El desinterés estatal para prevenir y juzgar los hechos. O, al menos, las graves insuficiencias que se han puesto de manifiesto.

El Estado ecuatoriano ha respondido a la CIDH que la Fiscalía General del Estado ha actuado, tanto en el caso de la matanza de 2003 como en la de 2013. Lo que no dice es que en ninguno de los dos casos se ha llegado a alguna parte, a alguna conclusión contundente ni a ninguna cosa que clarifique los hechos sucedidos.

Si ha actuado en el caso 2013, lo que ha logrado es cargar con todo el peso de la ley sobre los waorani (ahí no hay mucho que investigar pues ellos mismos se encargaron de contar su hazaña guerrera), confundir hechos, y, por supuesto, librar al Estado, pues no se llama a ningún funcionario para saber cómo se aplicaron leyes, alertas y protocolos cuando la muerte de los ancianos Ompure y Buganey durante esos 20 días antes de la expedición waorani de venganza (o justicia, para ellos). Si el Estado es quien tiene la obligación de proteger a esos pueblos, no cumplió a cabalidad con su deber.

El Estado ha avanzado en el papel. De acuerdo. Muy bien. Ecuador tiene un estupendo marco legal sobre el tema. El problema de las leyes es que no se aplican:

1. La Zona Intangible no es tan intangible. Lo han demostrado los madereros que han transitado por ella para cumplir una actividad ilegal.

2. Las empresas petroleras firmaron un Código de Conducta. En los casos que señalamos no han cumplido ese código... cuando una mujer y sus dos hijos fueron lanceados junto a un pozo (Hormiguero), la compañía Andes Petróleum no se retiró del lugar (2009). Tampoco lo hizo Repsol cuando ocurrió la muerte de Ompure y Buganey en el 2013. Cuando se escribe este artículo se han hecho ya trabajos de sísmica en Armadillo, donde el propio Ministerio de Justicia y antes el de Ambiente, han registrado huellas de su presencia.

3. El artículo 57 de la Constitución se refiere a los pueblos en aislamiento y dice que sus territorios son de posesión ancestral, intangible, irreductible y en ellos está vedada toda actividad extractiva. Al artículo Constitucional le falta solo un detalle: no dice cuáles son esos territorios. Las muertes han ocurrido dentro de esa zona intangible pero también fuera de ella lo que indica que los grupos aislados transitan fuera de las fronteras que ha establecido el Estado por una razón simple: no son esas las fronteras de sus territorios sino las fronteras de los bloques petroleros.

4. Tampoco dice que los límites de la llamada Zona Intangible han sido cambiados, movidos, negociados, de acuerdo a las presiones de la industria, sobre todo, hidrocarburífera, pero también de acuerdo a las necesidades de la colonización. 
Pasando al caso 2013, que merece especial atención, el Estado ecuatoriano manifiesta que la Fiscalía ha realizado una investigación, que hay unos acusados y un larguísimo proceso de juicio, incluso unos procesados -waorani- por haber cometido el delito, primero supuestamente de genocidio y, luego, de homicidio. Pero no dice, por supuesto, que unas autoridades a otras se prohibieron mutuamente acudir al lugar de los hechos y que apenas ocho meses después del suceso, se levantó la prohibición de ingresar al lugar ${ }^{7}$ de la matanza. Ocho meses es tiempo suficiente para que el clima y la carroña desaparezcan cualquier evidencia, o para que intrusos intervengan en la escena del crimen. Luego se ha investigado muy deficientemente. No se ha podido saber ni comprobar, siquiera, el número de víctimas.

En el banquillo de los acusados, donde han estado los waorani casi tres años en un juicio que no pueden comprender, debieran estar también representantes del Estado, pues no se trata solo de quién ejecuta el crimen, sino quién lo permite o lo provoca, quién no lo impide siendo su deber hacerlo, quien rehúye su responsabilidad, quién no investiga, quién no ha encontrado, en más de 10 años, ni a los patrones de la madera que operaban en el Yasuní (a pesar de que eran conocidos), ni a quienes han vendido armas y municiones y que han sido señalados como culpables de los últimos conflictos, ni a los que han invadido las tierras de los grupos indígenas, ni a los que han arrojado alimentos desde el aire.

No es lo mismo iniciar acciones legales que resolver un caso.

Han pasado casi tres años y aún no se llegan a las causas profundas del problema ni se establecen responsabilidades, salvo, el castigo, que parece implacable, contra miembros de un grupo indígena en contacto inicial, marginados históricamente de la sociedad nacional, al que ahora mismo se mantiene en un limbo jurídico incomprensible ${ }^{8}$. Es decir, a una injusticia, una injusticia mayor.

Los waorani de las familias de Dikaro y Yarentaro (los vengadores que participaron en el asalto a una casa tageri/taromenani), a duras penas saben leer o escribir, tienen menos de cuarenta años de contacto con la sociedad nacional, desconocen la ley, actuaron de acuerdo a sus antiguas tradiciones guerreras e hicieron lo que creían que debían hacer-venganza y castigo contra quienes mataron a los suyos dentro de su territorio-. Han estado acusados de genocidio y ahora de homicidio. Unas cosas que no pueden entender. Tampoco pueden entender ni qué es una instrucción fiscal, una Corte Constitucional, una audiencia para obtener medidas sustitutivas ni ningún otro término que tenga que ver con la justicia ordinaria.

En el primer juicio (por genocidio) la mitad de los participantes fueron detenidos en noviembre de 2013. La otra mitad quedó en libertad pero presos en sus casas pues casi no salían ni a la ciudad de Coca, ni al mercado de Pompeya, que les queda cerca para hacerse de productos. Escondidos. Preocupados. Enojados. Confundidos. Ellos sí en verdadero "aislamiento voluntario" (¿o forzado?). No tienen confianza en casi nadie. La tensión y la incertidumbre en el llamado "Bloque 16", operado por Repsol y donde están ubicadas sus comunidades, lleva casi tres años. Y en estos tres años, las autoridades no han podido ingresar, ni siquiera, a dialogar. Salvo el ministerio de Salud, que tiene su dispensario, ninguna otra institución pública se acerca a esas comunidades.

En el caso hubo siete detenidos y ocho personas con orden de captura. Una niña "rescatada" por las autoridades y otra niña más pequeña con papeles en regla en el registro civil, que vive en Dikaro, y que ha creado ya lazos afectivos con su nueva familia. Cuando los Waorani hablan de los Tagaeri-taromenani, en muchas de las comunidades, reclaman: "ellos quieren a las niñas", "vendrán a buscar a las niñas", "están buscando a las niñas".

7 En la documentación del proceso del juicio se pueden encontrar esas y otras perlas.

8 Primero se acusó a los waorani de Genocidio. Se detuvo a siete personas. Diez permanecieron libres en su comunidad. Luego de ocho meses de estar en prisión, dos, huyeron y fueron de vuelta a su comunidad. A los 10 meses, y luego de consultas a la Corte Constitucional, son liberados cinco de ellos. 17 deben presentarse cada 15 días ante un juez en Orellana (cosa difícil por la distancia de sus comunidades y por la situación económica de las 17 familias). Por otra parte se cambia el cargo, de Genocidio por Homicidio y se reinician las investigaciones, según rezan las providencias del caso y que son visibles en la web de la función judicial Ecuador. 
Los waorani se han gastado todos sus ahorros - muchos de ellos eran trabajadores de la compañía Repsol y tenían dinero ahorrado- en pagar a su defensa. Fueron librados de genocidio $\mathrm{y}$, en estos días (marzo 2016) los juzgarán por cargos de homicidio. Puede pasar que sean condenados. Puede, incluso, que sean condenados en ausencia. O que la pena sea mínima. O hasta que se archive el caso. Sea la que sea la decisión del jurado, se abonará con más incordia a la existente en esa región del olvido. Pero difícilmente, se resolverá la situación: guerra es guerra $\mathrm{y}$, el antídoto, siempre será un acuerdo de paz.

¿Habrán aprendido los guerreros que no hay que matar a sus enemigos? Creemos que no. De hecho, a la muerte de Caiga ya sonaron voces de aliento a otros grupos a que hicieran lo propio. Este aprendizaje, tal como ha sido llevado, puede resumirse, quizá, en que la próxima no contarán a nadie épicos relatos de guerra ni tomarán fotografías. Ningún camino para la paz. Ninguna sanción para quienes no cumplieron con su deber. Ninguna investigación o resultado serio para saber qué motivó a los tagaeri/taromenani a matar a los viejos Ompure y Buganey. Ninguna posibilidad de trabajar en la verdadera inclusión de los waorani en la sociedad occidental, con todos sus beneficios, derechos y obligaciones. Los waorani condenados como únicos responsables mientras el Estado muestra sus logros en papel: leyes, Constitución, frases rimbombantes, retórica conservacionista. Y además prepara, sin ruborizarse siquiera, el campo libre para que una empresa bielorusa trabaje en el campo más cercado a las casas donde habitan los ocultos. Y todo eso con la coartada perfecta: agotamos todas las instancias judiciales posibles.

\section{Los espectadores de esta historia}

Esta historia de muertes selváticas tiene varios actores. Y también, varios espectadores. Unos que se sentarán cómodos en la poltrona de sus prejuicios. En la primera fila repetirán hasta el cansancio que "es un conflicto entre clanes" y, como Pilatos, se lavarán las manos sin sacrificar una gota de petróleo aunque ahora no valga casi nada; otros, en la segunda fila, repetirán el desgastado argumento petrolero llegando a arengar sin pruebas -sería bueno tenerlas, claroque los petroleros pagan a los indios para matar a los Tagaeri y Taromenani. Alguno más se sentirá muy cómodo diciendo que hay que dejarlos libres como el viento y dejarlos es dejar que, en silencio, se organice una nueva partida, que esta vez será silenciosa y discreta, para acabar con ellos. Desaparecerán... pero no se darán cuenta, creerán aún en la selva infinita, desde la comodidad de sus prejuicios ideológicos, ignorando no solo que estos pueblos están cada vez más acorralados sino que, además, los vecinos se han multiplicado y que todos no caben en el mismo territorio.

A los pocos (que los hay), que han dicho que hay que dar mensajes de paz, que hay que hacer acuerdos, primero entre el pueblo waorani y el Estado ecuatoriano y luego, entre el pueblo waorani y las familias tagaeri/taromenani, dar alguna señal de paz en esta guerra repetida, serán descalificados y considerados etnocidas y promotores del contacto.

Así que para los de la primera fila y los de la segunda, la función ha de continuar así hasta el final de los días, hasta que desaparezcan estos pueblos. No falta mucho. Tienen los días contados: de no hacerse algo urgente, la venganza por la muerte de Caiga llegará. Y no quedará ninguno para contarlo. Quede en la conciencia de cada cual. 